\title{
Beijing's Declining Industrial Energy Intensity Trend: A Decomposition Analysis
}

\author{
Yong-Ke YUAN ${ }^{a},{ }^{*}$, Qin YANG and Qiang GAO \\ Beijing Advanced Innovation Center for Future Internet Technology, Beijing 100124, China \\ ayyk@bjut.edu.cn \\ ${ }^{*}$ Corresponding author
}

\begin{abstract}
Keywords: Industrial Energy Intensity, Technological Change, Structure Change, Capital-efficiency, Decomposition Analysis.
\end{abstract}

\begin{abstract}
The cause of the significant decline in China's energy intensity has been investigated by a number of decomposition studies, but most of them ignore the contribution of China's market-oriented economic reforms and the complicated difference among the provinces in China. This paper chose one city which is Beijing (the capital of China) to study the cause of the decline in energy intensity and carried out a decomposition analysis on a consistent set of data at three levels of 24 industrial departments: among the structural change, the technological change and the capital-efficiency which is the contribution of China's market-oriented economic reforms. From 2000 to 2010, Beijing experienced a decline in energy intensity of industry. Most previous studies attribute the decline to general technological effect or the role of structural. In this paper, we separate the capital-efficiency effect from the general technological effect, discuss the effect of the behavior of the government, and apply input-output techniques-structural decomposition analysis (SDA) to decompose overall energy intensity into three parts: technology, structure and capital-efficiency.

We find that: (1) the contribution of market-oriented reform in China could decrease the energy intensity; (2)technological change plays the dominant role; (3) the effect of structure change is not consistent; (4) the behavior of the government is very important.
\end{abstract}

\section{Introduction}

Since the start of economic reform in 1979, China's demand for energy has surged to fuel both its growing industrial and commercial sectors and the rapid rise in households' living standards (Crompton and $\mathrm{Wu}, 2005$ ). China consumed 1.39 billion tones of oil equivalent primary energy and accounted for $13.6 \%$ of the world total primary energy consumption in 2004 (BP, 2005).

But, by 2000 , the commercial energy intensity (energy/GDP) had decreased by $65 \%$ compared to 1980. Energy intensity declined in every year up till 2000 except for 1989, and since 2000 the decline in energy intensity slowed and energy intensity actually increased in 2003. ( Ma and Stem, 2008)

From 2013 to 2015, the industrial energy intensity has been decreasing. For example, in 2013, the value of the industrial energy intensity is 0.616 , while in the following years the values are 0.569 , 0.486 .

The cause of the significant decline in energy intensity has been investigated by a number of decomposition studies (Huang, 1993; Sinon and Levine, 1994; Lin and Polenske, 1995; Garbaccio et al., 1999; Fisher-Vanden et al., 2003; Fisher-Vanden etal., 2004; Wu and Cheng, 2006;Zhou and Li, 2006; Fan et al., 2007; Ma and Stern, 2008; Wu, 2010; Li, 2010). While most studies find that most important factors is technological change, there is disagreement on the role of structural change - a shift in the mix of industries. Many found that structural change has played a minor role in reducing energy intensity. However, Garbaccio et al(1999) found that structural change actually increased energy intensity between 1987 and 1992. Fisher-Venden etal. (2003) similarly found an intensity-increasing effect that 1-digit SIC sector level from 1997 to 1999. Ma and Stern (2008) reached the same conclusion as Fisher-Venden etal. (2003). By using survey data on approximately 
2500 of China's industrial enterprises, Fisher-Vanden etal.(2004) found that efficiency effects at the firm level had contributed to $47 \%$ of the industrial energy intensity decline during 1997-1999.

In Chinese magazines, there are similar conclusions as the above. For example, Qi and Chen (2006), Wu and Cheng (2006) and Wu (2010) argued that the decrease of energy intensity is mainly due to the improved energy efficiency of industries as a whole and compared to efficiency, industry structure has much less influence on the energy intensity. Li(2010) argued that because of Chinese country condition, the effect that the industrial structure has brought into the energy consumption is not weak gradually, but appears not yet obviously. Zhang et al (2007) and Zhou and Li (2006) argued that the analyzing result about the factors influencing energy intensity in different phase is different.

Fan et al. (2007) discussed the contribution of China's market-oriented economic reforms to changes in energy intensity. With the exception of energy intensity, the carbon intensity changes resulting from fossil fuel consumption can also be decomposed into sectoral effects and efficiency effects. Ma and Stern (2008) used LMDI techniques to decompose changes in energy intensity in the period 1980-2003.According to the data of output and energy consumption of six industrials in 30 provinces from 2002 to 2012, Zhang and $\mathrm{Yu}(2015)$ designed the measure index of regional industrial structure evolution based on Moore value, and analyzed the impact of industrial structure evolution on energy intensity using dynamic panel GMM method. Research shows that the industrial structure evolution does significantly play a promoting effect of reducing energy intensity. Hang song etal(2016) computes and analyzes the sources of the changes of energy intensity in China during the period 2001-2013 by using the decomposition method.

The above arguments about the causes of the significant decline in China's energy intensity all ignore the contribution of China's market-oriented economic reforms except for Fan et al.(2007) who did not use the method of the decomposition analysis. In this paper, we carry out a decomposition analysis on a consistent set of data at three levels of 24 industrial departments: among the structural change, the technological change and the capital-efficiency. The structural change and the technological change have been discussed by many scholars. In this paper we use its sector's energy consumption per compensation of capital to describe the technological change instead of energy consumption per unit of ith sector's GDP. The capital-efficiency is a new factor used to investigate the cause of the significant decline in energy intensity. For example, when the production demand decreases, the output of the manufacture industry would be small, and the compensation of employees would be reduced, but the capital could not be down at once because most of the manufactories are state-owned. So there would be some energy consumption on the capital-efficiency. As we know, China's market-oriented economic reform is to improve the market strength. In other words, the capital-efficiency is a factor which is the contribution of China's market-oriented economic reforms.

The paper is organized as follows. Section 2 introduces the method used to decompose the energy intensities. Section 3 explains where the data is got. Section 4 discusses the results. Section 5 summers this paper.

\section{Methods}

There are two broad categories of decomposition techniques (Hoekstra and Van der Bergh, 2003): input-output techniques- structural decomposition analysis (SDA) and disaggregation techniques-index decomposition analysis (IDA). The SDA approach is based on input-output coefficients and final demands from input-output table while IDA framework uses aggregate input and output data that are typically at a high level of aggregation than input-output tables.

There are a variety of different indexing methods that can used in IDA. Ang (2004) provides a useful summary of the various methods and their advantages and disadvantages. Some of these have been applied in analyses of China's energy intensity. Huang(1993) use multiplicative arithmetic mean Divisia indices to decompose energy intensity in Chinese secondary industry and the six sectors into which he divided in the period 1980-1988 into the effects of structural change and improvements in energy intensity. Sinton and Levine(1994) used a Laspeyres index to determine 
the relative roles of structural change and technological effect in China's industrial sector between 1980 and 1990 with three different sets of data and found similar results to Huang (1993). While the previous studies use IDA approaches, Lin and Polenske (1995) used SDA to study China's energy use between 1981 and 1987. The economy was disaggregated into seven sectors: agriculture, energy, heavy industry, light industry, construction, and transport and services. Garbaccio et al (1999) also applied SDA to study the decline intensity between 1987 and 1992, disaggregating the economy into 29 sectors.

There are two advantages of SDA. One advantage of SDA is that the input-output model includes indirect demand effects-demand for inputs from supplying sectors that can be attributed to the downstream sector's demand - so that SDA can differentiate between direct and indirect energy demands. SDA has another advantage of being able to distinguish between a range of technological effects and structural effects that are not possible in IDA model. Therefore we have adopted this method.

Suppose that there are $\mathrm{N}$ sectors in Beijing's industry, $\mathrm{E}(\mathrm{t})$ is the overall energy intensity in year $\mathrm{t}$, $e_{i}(t)$ is the energy intensity of the ith sector in year $t, C_{i}(t)$ is the capital-efficiency of the its sector in year $\mathrm{t}$, and $\mathrm{p}_{\mathrm{i}}(\mathrm{t})$ is the proportion of the its sector's added value $(\mathrm{Gi})$ to the overall added value $(\mathrm{G})$ in year $t$. The overall energy intensity can be written as following:

$$
\mathrm{E}(\mathrm{t})=\mathrm{ES} / \mathrm{G}
$$

Where ES is the overall industrial energy consumption in Beijing and can be written as following:

$$
\mathrm{ES}=\sum_{1}^{\mathrm{N}} \mathrm{ESi}
$$

Where ESi is the its sector's energy consumption, can be written as following:

$$
\mathrm{ESi}=\mathrm{e}_{\mathrm{i}} * \mathrm{G}_{\mathrm{i}} / \mathrm{C}_{\mathrm{i}}
$$

where the energy intensity of the its sector, $e_{i}=E S i / C G i$, and $C_{i}=G_{i} / C G i . C G i$ is the compensation of capital in its sector.

Substituting (3) and (2) into (1), yields

$$
\mathrm{E}(\mathrm{t})=\sum_{1}^{\mathrm{N}} \mathrm{ei}(\mathrm{t}) * \mathrm{pi}(\mathrm{t}) / \mathrm{Ci}(\mathrm{t})
$$

The change of overall energy intensity can be written as following:

$$
\begin{aligned}
& \Delta \mathrm{E}(\mathrm{t})=\mathrm{E}(\mathrm{t})-\mathrm{E}(0)=\sum_{1}^{\mathrm{N}}\left[\mathrm{ei}(\mathrm{t}) * \frac{\mathrm{pi}(\mathrm{t})}{\mathrm{Ci}(\mathrm{t})}-\mathrm{ei}(0) * \frac{\mathrm{pi}(0)}{\mathrm{Ci}(0)}\right] \\
& =\sum_{1}^{\mathrm{N}} 0.5 *[\mathrm{ei}(\mathrm{t})-\mathrm{ei}(0)] * \frac{[\mathrm{pi}(\mathrm{t})+\mathrm{pi}(0)]}{\mathrm{Ci}(\mathrm{t})}+0.5 *[\mathrm{pi}(\mathrm{t})-\mathrm{pi}(0)] * \frac{[\mathrm{ei}(\mathrm{t})+\mathrm{ei}(0)]}{\mathrm{Ci}(\mathrm{t})}+\mathrm{ei}(0) * \mathrm{pi}(0) *\left[\frac{1}{\mathrm{Ci}(\mathrm{t})}-\frac{1}{\mathrm{Ci}(0)}\right] \\
& =\sum_{1}^{\mathrm{N}} 0.5 * \Delta \mathrm{ei} * \frac{[\mathrm{pi}(\mathrm{t})+\mathrm{pi}(0)]}{\mathrm{Ci}(\mathrm{t})}+0.5 * \Delta \mathrm{pi} * \frac{[\mathrm{ei}(\mathrm{t})+\mathrm{ei}(0)]}{\mathrm{Ci}(\mathrm{t})}+\mathrm{ei}(0) * \mathrm{pi}(0) * \Delta \mathrm{Ci}
\end{aligned}
$$




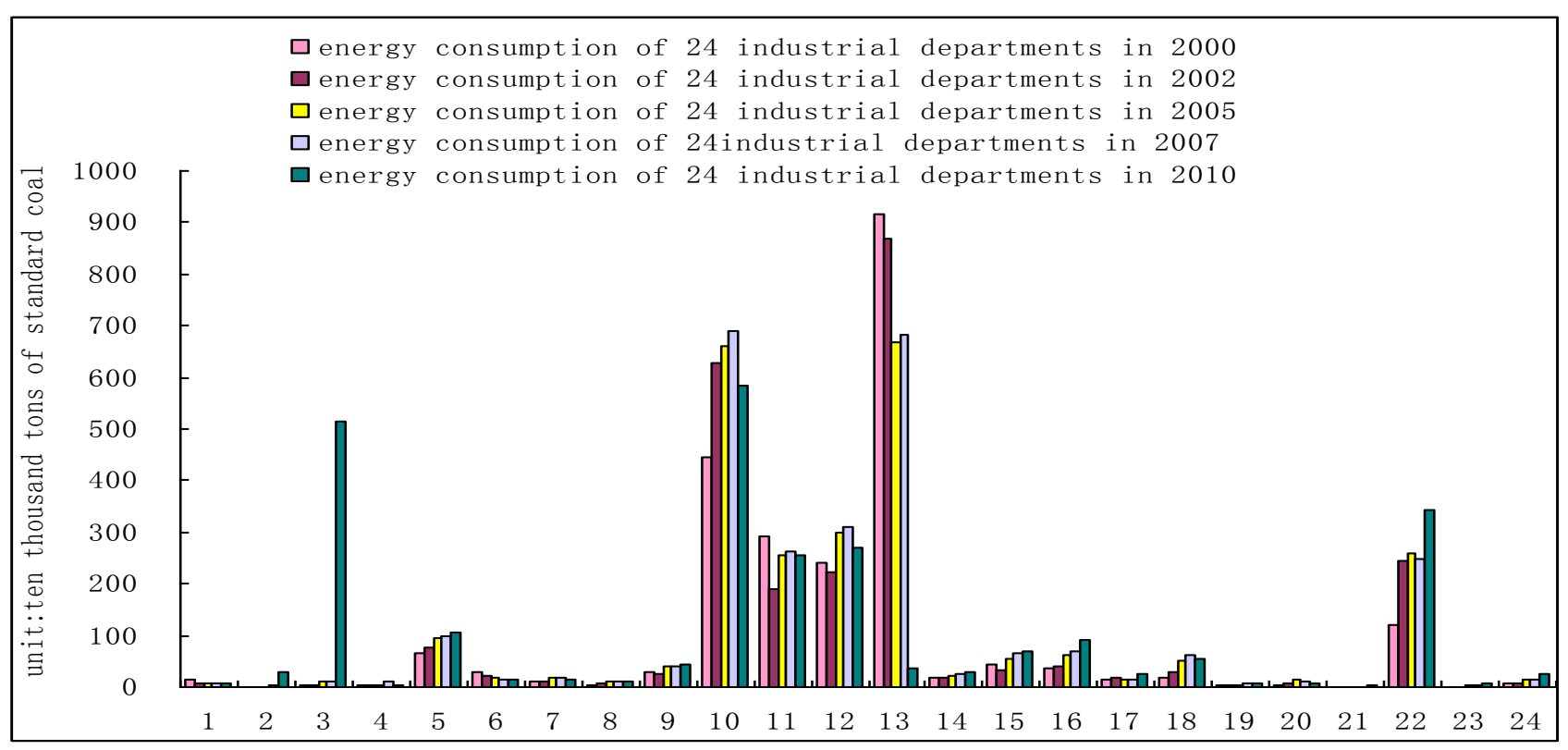

Fig. 1 Energy Consumption of 24 Sectors in Beijing in 2000, 2002, 2005, 2007 and 2010 Source: BSY

Where the first part is caused by technology, the second part is caused by structure, and the last one is caused by the capital-efficiency.

\section{Data}

We compiled data from various issues of the Beijing Statistical Yearbook (BSY) and Beijing Energy Statistical Yearbook (BESY). The energy data and GDP data are in grams of standard coal equivalent (GSCE) and RMB yuan respectively. The whole economy is divided into 24 sectors.

The different sector also has different energy consumption in different period (Fig.1). For example, the energy consumption of oil processing and coking and nuclear fuel processing sector, whose code number is 10 , is 6.892 million tons of standard coal in 2007, while energy consumption of metal smelting and rolling processing sector, whose code number is 13, is 6.84 million tons standard coal in 2007. But the energy consumption of No.10 reduced to 5.8498 million tons standard coal in 2010, while the energy consumption of NO.13 plunged for 373100 tons of standard coal in 2010.

\section{Results and Comparison}

In this section, we apply the proposed model (Eq.4) to the two sets of Data and explore the contributions of the various effects to the changes in Beijing's industrial energy intensity.

We first conduct the complete decomposition over the period from 2000 to 2010.Table 1 and table 2 shows the decomposition results. Most of the time, the change in technology $(\Delta \mathrm{e})$ and capital-efficiency $(-\Delta \mathrm{C})$ could decrease the energy intensity as we expected. The accumulated (period-wise) effect is an decrease of $2.845 \mathrm{GSCE} /$ constant RMB, which accounts for $140.6 \%$ of the total intensity change $(\Delta \mathrm{E})$ in absolute value. The structural effect $(\Delta \mathrm{p})$ sometimes decreases the energy intensity while it sometimes increases the energy intensity. The accumulated structural effect at the sectors decreases energy intensity, accounting for $5.9 \%$ of the accumulated total energy intensity decrease. Most of the contribution occurred over the period of 2005-2007. The accumulated effect of capital-efficiency is an decrease of 0.94 GSCE/constant RMB, which accounts for $46.46 \%$ of the total intensity change $(\Delta \mathrm{E})$ in absolute value. The residual values are all very small and could be cut down. 
Table 1 Complete decomposition of energy intensity change (2000-2010)

Note:

\begin{tabular}{cccccc}
\hline & $\Delta \mathrm{E}$ & $\Delta \mathrm{e}$ & $\Delta \mathrm{p}$ & $\Delta \mathrm{C}$ & $\mathrm{R}$ \\
\hline $2000-2002$ & -0.2377 & -0.3177 & -0.6943 & 0.7743 & 0.0000 \\
$2002-2005$ & -1.2152 & -2.6601 & 1.2650 & 0.1790 & 0.0009 \\
$2005-2007$ & -0.2030 & 0.6499 & -1.0469 & 0.1943 & -0.0003 \\
$2007-2010$ & -0.3675 & -0.5170 & 0.3569 & -0.2076 & 0.0002 \\
$2000-2010$ & -2.02342 & -2.8450 & -0.1193 & 0.9400 & 0.0008 \\
\hline
\end{tabular}

(1) Data Source: BSY1 BESY, authors' calculation; GSCE/RMB (constant prices).

(2) Negative values indicate decreasing energy intensity.

(3) $\Delta \mathrm{E}$ is the change of (Beijing industrial) overall energy intensity

(4) $\Delta \mathrm{e}, \Delta \mathrm{p}$, and $\Delta \mathrm{C}$ are effects of technological change, structural shift at sectors and capital-efficiency respectively.

(5) $\mathrm{r}$ is the residual value.

Table 2 Complete decomposition of energy intensity change in percentage (\% of $\Delta \mathrm{e})(2000-2010)$

Note:

\begin{tabular}{cccccc}
\hline & $\Delta \mathrm{E}$ & $\Delta \mathrm{e}$ & $\Delta \mathrm{p}$ & $\Delta \mathrm{C}$ & $\mathrm{R}$ \\
\hline $2000-2002$ & 100 & 133.67 & 292.10 & -325.77 & 0.00 \\
$2002-2005$ & 100 & 218.90 & -104.09 & -14.73 & -0.08 \\
$2005-2007$ & 100 & -320.10 & 515.64 & -95.68 & 0.14 \\
$2007-2010$ & 100 & 140.69 & -97.12 & 56.49 & -0.06 \\
$2000-2010$ & 100 & 140.60 & 5.90 & -46.46 & -0.04 \\
\hline
\end{tabular}

(1) Data Source: BSYl BESY, authors' calculation.

(2) Negative values indicate increasing energy intensity and positive values decreasing energy intensity.

Our results also show that technological change plays the dominant role in decreasing energy intensity, which is consistent with the conclusions of previous empirical studies. It is noteworthy that the effect of technology increases energy intensity over the period of 2005-2007 because of the behaviors of the government. For example, China's government launched a vigorous program to reverse the trend of rising national energy intensity and Beijing's government reduced productions of 9 sectors, most of which are high-energy-consumption (table 3 ). When the enterprises did not get constant returns to scale in its energy consumption, the effect of technology would increase energy intensity. So the excessive behavior of the government would reverse the effect of technology.

Our results also show that structural effects explained a relatively larger share of the total changes in the period of 2000-2002 and the period of 2005-2007, but the accumulated structural effect at the sectors accounted for $5.9 \%$ of the accumulated total energy intensity decrease, which is consistent with the conclusions of previous empirical studies.

But the main cause of the structure shift at sectors is the behaviors of the government. For example, in the period of 2005-2007, there are 9 sectors whose productions were forced to be reduced so that the sky of Beijing would be cleaner in 2008 than ever. These 9 sectors are: coal mining and washing sector, metal ore mining sector, non metallic minerals and mining of other ores sector, petroleum processing sector, metal smelting and rolling processing sector, metal products sector, manufacture of artwork and other manufacturing sector, waste scrap sector, and water production and supply sector. Metal smelting and rolling processing sector is the most energy consumption sector which consumes energy of $667.72 * 10^{4}$ TSCE in 2005, and petroleum processing sector is the second most energy consumption sector which uses energy of $662.19 * 10^{4}$ TSCE in 2005. They consume many more energy respectively than the following one. For example, the third most energy consumption sector consumes energy of $299.40 * 10^{4}$ TSCE in 2005 . The 9 sectors' GDP is 43.92 billion Yuan in 2005, which is $27 \%$ of the total industrial GDP in Beijing, while it is 21.00 billion Yuan in 2007, which is $10 \%$ of the total industrial GDP. But 9 sectors' 
energy consumption increases from $1409.11 * 10^{4}$ TSCE in 2005 to $1454.61 * 10^{4}$ TSCE in 2007 . The effect of the Government's behavior is that the energy consumption decreases $1 \%$ by the 9-GDP decreasing $17 \%$.

Table 3 Effects of structural shift (2005-2007)

\begin{tabular}{ccccccc}
\hline & T-GDP & $\begin{array}{c}9- \\
\text { GDP }\end{array}$ & $\begin{array}{c}\text { 9-GDP/ } \\
\text { T-GDP }\end{array}$ & \multirow{2}{*}{ T-EC } & 9-EC & $\begin{array}{c}\text { 9-EC/ } \\
\text { T-EC }\end{array}$ \\
\hline 2005 & 1614.16 & 439.17 & 0.27 & 2017.71 & 1409.11 & 0.70 \\
2007 & 2078.60 & 209.97 & 0.10 & 2097.47 & 1454.61 & 0.69 \\
\hline
\end{tabular}

Note:

(1) Data Source: BSY1 BESY, authors' calculation; GSCE/RMB (constant prices)

(2) T-GDP is the total industrial GDP and 9-GDP is the sum of 9 sectors' GDP

(3) T-EC is the total industrial energy consumption and 9-EC is the sum of 9 sectors' energy consumption.

Our results show that capital-efficiency plays important role in decreasing energy intensity, which is not investigated by the previous empirical studies. From Eq.4, capital-efficiency is equal to $-\Delta \mathrm{C} * \mathrm{C}(\mathrm{t}) * \mathrm{C}(0)$, so its effect is in the opposite direction of $\Delta \mathrm{C}$. China's market-oriented economic reform is to improve the market strength. In other words, capital would play more important role in China than before, so the capital-efficiency is a factor which is the contribution of China's market-oriented economic reforms. It is noteworthy that the effect of capital-efficiency increases energy intensity over the period of 2007-2010 because of Beijing Olympic Games' buildings. The investment in Beijing Olympic Games' buildings is huge and asset belongs to the Government. So the capital-efficiency is decreasing over this period.

\section{Conclusions}

Our results confirm the dominant role of technological change over the entire period of 2000-2010 except for the period of 2005-2007. In the period of 2005-2007, the behavior of Beijing government changed the constant returns to scale in energy consumption in some sectors, and the effect of technological change in this period increase the energy intensity. This conclusion means that constant returns to scale in energy consumption are the conditions that the effect of the technological change could decrease the energy intensity.

Our results also confirm the change role of structural effects which is consistent with the conclusions of previous empirical studies. Over the period of 2000-2002 and the period of 2005-2007, structural effects decrease the energy intensity, while over the period of 2002-2005 and the period of 2007-2010, they increase the energy intensity.

Our results argue that the effects of the contribution of market-oriented reform could decrease the energy intensity. Over the entire period of 2000-2007, the effects of capital-efficiency decrease the energy intensity. But over the period of 2007-2010, the effects of capital-efficiency increase the energy intensity.

Our results also argue that the behavior of the government in Beijing is very important. The structural effects could decrease the energy intensity over the period of 2005-2007 by the behavior of the government which reduced the productions of 9 sectors, while the effect of technological change increases the energy intensity over the same period. It is the effect of behavior of the government that changes the capital-efficiency by plan-oriented Beijing Olympic Games' building.

\section{References}

[1] Ang. B. W., 2004. Decomposition analysis for policymaking in energy: which is the preferred method. Energy Policy 32, 1131-1139.

[2] BP, 2005. Statistical Review of World Energy. http://www.bp.com/statisticalreview. 
[3] Chunbo Ma, David I. Stern. China's changing energy intensity trend: A decomposition analysis. Energy Economics 30 (2008) 1037-1053.

[4] Crompton. P., Wu, Y.R., 2005. Energy consumption in China: past trends and future idrection. Energy Economics 27, 195-208.

[5] Fan, Y., Liao, H., Wei, Y.M., Can market oriented economic reforms contribute to energy efficiency improvement? Evidence from China. Energy Policy, 2007, 35(4):2287-2295.

[6] Fisher-Vanden, K., et al., What is driving China's decline in energy intensity? Resource and Energy Economics,2004, 26 (1):77-97.

[7] Fisher-Vanden, Karen, Jefferson, Gary H., Liu, Hongrnei, Tao, Quan, 2003. What is driving China's decline in energy intensity. Resource and Energy Economics 26, 77-97.

[8] Garbaccio, R.F., Ho, M.S., Jorgenson, D.W., 1999. Why has the energy-output ratio fallen in China. Energy Journal 20(3), 63-91.

[9] Han song,Zhang baosheng, Tang xu,Qishuai and Meng fanyan. Study on the Driving Factors in China's Energy Intensity Change-Based on LMDI Decomposition Technique. Modern Economic Science, 2016,38(5):89-97,127

[10]Hoekstra, R., Van der Bergh, J.C.J.M., 2003. Comparing structural and index decomposition analysis. Energy Economics 25(1), 39-64.

[11]Huang,J.P.,1993. Industrial energy use and structural change: a case study of the People's Republic of China, Energy Economics 15, 131-136.

[12]Lanhong Li. The Theory of Adjustment of China's Industrial Structure in Aspect of Energy Consumption, Journal of Shandong Normal University(Humanities and Social Sciences), 2010(2): 135-139.

[13]Lin, X., Polenske, K.R., 1995. Input-output anatomy of China's energy use changes in the 1980s. Economics Systems Reseach 7(1), 67-84.

[14]Qiaosheng $\mathrm{Wu}$ and Jinhua Cheng, Change in Energy Consumption Intensity and the Main Factors during the Process of China's Industrialization-An Empirical Analysis based on the Decomposition Model, Journal of Finance and Economics,, 2006(6):75-85.

[15]Qiaosheng Wu, Energy Intensity Changes and Its Influenciing Factors During the Industrialization in China, Economic Theory and Business Management,2010(5):44-50.

[16]Rui Zhang, Rijia Ding and Lanlan Yin. The Change of Structure influence on Chinese Energy Intensity, Statistics and Decision, 2007(10): 73-74.

[17]Sinton,J.E.,Levine, M.D., 1994. Changing energy intensity in Chinese industry: the relative importance of structural shift and intensity change, Energy policy 22, 239-255.

[18][18] Yong Zhou and Lianshui Li, The Action of Structure and Efficiency on Chinese Energy IntensityAn-Empirical Analysis Based on AWD, Industrial Economics Research,2006(4):68-74.

[19] Zhang yong and Pu yongjian. Industrial Structure Evolution and Its Impact on Energy Intensity. Industrial Economics Research, 2015,75(2):15-22. 